\title{
Stimulus consequences of postreward confinement
}

\author{
JAMES BOWEN
}

ARLINGTON STATE COLLEGE OF THE UNIVERSITY OF TEXAS

Three groups of 12 rats were trained in a straight alley runway. Group $R$ received regular 100 per cent reward. Group $\mathrm{R}-\mathrm{C}$ received postreward confinement ( $\mathrm{PRC}$ ). Group $S$ was shifted from continuous reward to $\mathrm{PRC}$. Then all $\mathrm{Ss}$ received extinction trials. Generalization decrement occurred in Group $S$ following the shift to $\mathrm{PRC}$. Group $\mathrm{R}$ extinguished more rapidly than the other two groups which did not differ.

Capaldi \& Poynor (1966) suggested that the aftereffect generated by delayed reward $\left(\mathrm{S}^{D}\right)$ has some of the properties of the after-effects of both reward $\left(\mathrm{S}^{\mathrm{R}}\right)$ and nonreward $\left(\mathrm{S}^{\mathrm{N}}\right), \hat{i}_{\circ} e_{\circ}$, on a stimulus continuum $\mathrm{S}^{\mathrm{D}}$ lies between $\mathrm{S}^{\mathrm{R}}$ and $\mathrm{S}^{\mathrm{N}}$. One might reasonably expect, then, though it does not necessarily follow, that the after-effects generated by postreward confinement (PRC) would also have some of the properties of both $\mathrm{S}^{\mathrm{N}}$ and $\mathrm{S}^{\mathrm{R}}$. This assumption leads to at least two testable hypotheses: (1) Ss shifted to PRC from regular 100 percent reward should manifest generalization decrement since $\mathrm{S}^{\mathrm{PRC}}$ would be substituted for $\mathrm{S}^{\mathrm{R}}$ on those trials following the shift to PRC. (2) PRC should generate greater resistance to extinction than regular 100 percent reward. From the assumption that after-effects become conditioned to responses, it follows that SPRC will become conditioned to the instrumental response in one group and $S^{R}$ in the other. Since $S^{N}$ occurs during extinc-

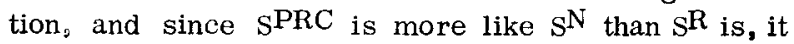
follows that $\mathrm{S}^{\mathrm{N}}$ will get more generalized habit strength from $S$ PRC than from $S^{R}$. Thus the PRC group should be more resistant to extinction than the regular 100 percent group.

There are no data concerning the first hypothesis. The data concerning the second hypothesis are conflicting. Fehrer (1956) observed that PRC generated more resistance to extinction than a regular 100 percent group. In a replication of Fehrer, Cogan (1966) found no difference.

\section{Method}

The Ss were 36 naive Wistar strain albino rats which were about 90 days old at the beginning of training. The apparatus was a straight alley runway 72 in. in overall length, 5 in. wide, and enclosed by 6 in. high sides covered with hinged hardware cloth. A $2.5 \mathrm{in.} \mathrm{high} \mathrm{metal} \mathrm{food} \mathrm{cup} \mathrm{was} \mathrm{attached} \mathrm{to} \mathrm{the} \mathrm{end}$ of the alley. The lid to the food cup was mechanically controlled. A 10 in. treadle at the beginning of the alley started a Standard Electric timer when $\mathrm{S}$ was placed onto it. A photocell mounted 4 in. from the end of the goal section stopped the timer when the beam was broken. A guillotine type door placed $14 \mathrm{in.}$ from the end of the alley prevented retracing. The entire apparatus was painted a flat gray.

The $\mathrm{Ss}$ were maintained on a $23-\mathrm{hr}$. deprivation schedule for eight days. On the first five days the Ss were handled in groups of 12 for $30 \mathrm{~min}$. before being fed; on the last three the Ss explored the apparatus in groups of four for $15 \mathrm{~min}$. before being fed. The Ss were then randomly divided into three groups of 12 each and Day 1 of experimental training began on the ninth day. Group $R$ received $10 \mathrm{sec}$. reward for 60 trials. Group $\mathrm{R}-\mathrm{C}$ received $10 \mathrm{sec}$. reward followed by 30 sec. PRC for 60 trials. Group $S$ received $10 \mathrm{sec}$. reward for 48 trials and then was shifted to $10 \mathrm{sec}$. reward-30 sec. PRC for 12 trials. All Ss were then given 12 extinction trials. Half of each group was confined for 10 sec. on each extinction trial; the other half for $40 \mathrm{sec}$. Each S received six trials per day. The intertrial interval was $15 \mathrm{sec}$. The reward was access to $97 \mathrm{mg}$ Noyes pellets. On all $10 \mathrm{sec}$. reward trials, the lid to the food cup was closed before $S$ was removed from the goal box. A $60 \mathrm{sec}$. running time criterion was used on all tria!s.

\section{Results}

The mean $\log$ running times on Day 8 were .61 for Group R, .54 for Group S, and .32 for Group R-C. An analysis of variance revealed that the differences were not significant $(F=3.2, \mathrm{df}=2 / 33, \mathrm{p}>.05)$. The means for Day 9 were .45 for Group R, .56 for Group $\mathrm{S}$, and .32 for Group R-C. Some of these differences were significant $(F=4.9, d f=2 / 33, p<.05)$. Duncan's Multiple Range Test revealed that Group $S$ differed from Group $\mathrm{R}-\mathrm{C}(\mathrm{p}<.05)$. No other differences were significant. However, when the differences between Groups $R$ and $S$ are analyzed across Days 8 and 9 , the Days by Groups interaction is significant $(F=4.9$, $\mathrm{df}=1 / 23, p<.05)$. The means for Day 10 were .30 for Group R, .38 for Group S, and .26 for Group R-C. The differences were not significant $(F=2.4, \mathrm{df}=2 / 33$ ).

The mean log running time during extinction was 1.26 for Group R, .95 for Group S, and .95 for Group R-C. A 2 by 3 (Confinement by Groups) factorial design revealed a significant groups difference $(F=6.01$, $\mathrm{df}=2 / 30, \mathrm{p}<.01)$. Duncan's Multiple Range Test indicated that Group $\mathbf{R}$ differed from the other groups $(p<.05)$. There was no difference as a function of confinement time $(F=2.44, \mathrm{df}=1 / 30)$. The Groups by Confinement interaction was also nonsignificant $(F=.99$, $\mathrm{df}=2 / 30)$.

Discussion

The Days by Groups interaction tended to confirm 
the generalization decrement hypothesis, though a main effect difference would be more convincing. The significant groups difference in extinction confirmed the second hypothesis. The equivalence of Groups $\mathrm{S}$ and $\mathrm{R}-\mathrm{C}$ was not surprising. $\mathrm{SPRC}$ is conditioned on all trials except the first in PRC training since SPRC is present on N-1 acquisition trials and is always associated with immediate reward. With 50 percent reward, $\mathrm{SN}$ is conditioned to the instrumental response on only half the acquisition trials at best. Thus PRC training should generate maximum resistance to extinction with a relatively small number of trials.

The discrepancy between Fehrer and Cogan is apparently due to the difference in number of extinction trials given. Fehrer gave 12 trials; Cogan gave 50. There seems to be an initial difference in resistance to extinction with both regular 100 percent and PRC groups reaching the same lower asymptote rapidly. Over a long extinction series, then, no difference would be expected.

\section{References}

Capaldi, E. J., \& Poynor, H. Aftereffects and delay of reward. $J$. exp. Psychol., 1966, 71, 80-88.

Cogan, Dennis C. Post-reinforcement delay in extinction: a failure to replicate. Psychon. Sci., 1966, 6, 343-344.

Fehrer, Elizabeth. Effects of reinforcement and of pre- and postreinforcement delays on learning and extinction. J. exp. Psychol., 1956, 52, 167-176.

\section{Note}

1. This research was supported in part by Public Health Service Research Grant MH 11694-01 from the National Institute of Mental Health.

\section{Errafum}

HOMMEL, L. S., \& ALTMAN, H. B. Resistance to extinction following exposure to a complex situation. Psychon. Sci., 1966, 6 (9), 415-416.-Page 416, paragraph 3 should read as follows: "groups (P vs. C: $t=2.319, d f=12, p<.05 ; P$ vs. $N: t=2.373, d f=12$, $p<.05$; C vs. $N: t=4.762, d f=12,{ }^{\prime \prime}$ 